\title{
NATIONAL BUREAU OF STANDARDS REPORT
}

\section{NBS PROJECT}

311.05-11-3110561
May 27,1971

NBS REPORT

10421

\section{Progress Report \\ on \\ RESEARCH TECHNICS USED IN EVALUATING DENTAL MATERIALS}

\author{
G. C. Paffenbarger*, DDS and N.W. Rupp**, DDS \\ * Senior Research Associate Emeritus, American Dental \\ Association Research Unit, National Bureau of Standards, \\ Washington, D. C. 20234. \\ ** Research Associate for the American Dental Association \\ Research Unit, National Bureau of Standards, Washington, \\ D. C. 20234.
}

This investigation was supported in part by the National Institute of Dental Research and is part of the dental research program conducted by the National Bureau of Standards, in cooperation with the American Dental Association; the United States Army Medical Research and Development Command; the Dental Sciences Division of the School of Aerospace Medicine, USAF; the National Institute of Dental Research; and the Veterans Administration.

\section{IMPORTANT NOTICE}

NATIONAL BUREAU OF S for use within the Government. and review. For this reason, $t$ whole or in part, is not auth Bureau of Standards, Washing the Report has been specitical
Approved for public release by the Director of the National Institute of Standards and Technology (NIST) on October 9, 2015. ress accounting documents intended is subjected to additional evaluation re listing of this Report, either in the Office of the Director, National , by the Government agency for which copies for its own use.

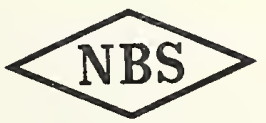

\section{U.S. DEPARTMENT OF COMMERCE}





\section{Introduction}

There is nothing that will take the vagueness out of one's thoughts as much as reduction of them to writing. This does not mean that all the haze is gone--it just infers that the fogginess is somewhat dispersed, as will become evident when one takes the written version of one's thoughts and attempts to carry them out in the laboratory. Here the refinement is only partial and almost always requires further improvement. Such improvement comes when others read the revised version of the procedure and attempt to follow the written instructions. Precise description of test methods is a difficult task which requires meticulous care.

All of the foregoing factors apply to any research procedures used in evaluating materials of any type. However, today your speaker is just hitting a few highlights in describing some research technics used in evaluating dental materials.

\section{Specifications}

A specification for a material should characterize it by physical, chemical and biological tests with minimum and maximum value limits for the pertinent properties. Thus, it should be possible to so design the specification that inferior or unsatisfactory materials would be rejected and that only suitable materials would comply with the requirement of the specifications.

The design of suitable specification tests that are both reliable and valid is no mean research task. By reliable it is meant that the tests can be repeated by 
different laboratories with satisfactory agreement in results. By valid it is meant that the laboratory testing will predict the behavior of the materials in service. So in order to obtain a high degree of validity it is necessary to design the laboratory test to simulate the conditions of use as closely as possible and at the same time have a very brief test. In other words, the laboratory test should predict in one hour or one day or in one week what the clinical behavior will be after several years. It is usually necessary to characterize materials, especially new materials, first in the laboratory and then clinically. If there is a high degree of correlation between the laboratory and the clinical test results, then the laboratory test does indeed have a high degree of validity.

Since the laboratory test must be brief it is often necessary to use abusive testing--made abusive by exaggerating the severity of normal deteriorating influences of use or by increasing the frequency of them or both.

\section{Service Tests}

If you wish to know how a material will behave in service, the most direct answer can be obtained by using it in service and in observing its behavior. This is not an easy task as good clinical testing requires a proper and definitive characterization of the material being tested. This is lacking in so many clinical tests. Even if one did have the personnel, the facilities and the finances it is ridiculous to test only by clinical trial because progress is slow, costly and often indecisive.

Whenever a practitioner is using a material he is usually giving it a service test consciously or unconsciously. However, it should be iterated over and over again that since 
much clinical service testing is not controlled and has little or no discipline in it it has little value. Usually the trial use of a material is conducted by a large group of practitioners with little or no centralized control so that the securing of reliable service statistics is difficult, if not impossible.

Therefore, prior testing in the laboratory is absolutely imperative in modern technology as the gap between the raw materials becomes greater and greater. Hence, the laboratory testing of materials is becoming more and more important.

\section{Other Tests}

In addition to actual testing of the material in a laboratory one can assemble the material into a structure or appliance and test it. There are many examples where such tests are imperative because assembling the material into a structure will require fabrication procedures that may vastly change the properties. Some examples are stress concentration, surface treatment and thermal history.

If the structure or appliance is large it is often desirable to prepare a smaller model and test it but this is not really encountered in biomaterials. In fact, in dental materials it is often necessary to make comparatively miniature physical test specimens as conventional sizes alter values for significant properties.

Some rules for the formulation of specifications

Charpy, (2) the old master, gave in 1907 some excellent advice that is as good today as the day he gave it decades ago: 
(a) Avoid composition requirements and define the material by performance tests.

(b) Give a meticulously precise description for all tests.

(c) Avoid all vagueness that permits or necessitates any arbitrary decisions on the part of the personnel during the testing.

(d) Specify the relationship between the precision of the testing machines and the precision required in the results of the tests.

(e) State how the data are to be derived and recorded.

It is difficult to go in the wrong direction if one adheres to these.

\section{Biological Testing}

Most of the discussion on physical testing applies equally well to biological testing. To recapitulate--reduce the test method to writing, conduct the necessary laboratory tests, design the tests to simulate actual conditions of use, develop laboratory screening tests prior to biological testing in order to establish their degree of reliability and validity.

One has to use certain axioms in the design of laboratory screening tests prior to tests employing animals or humans. One axiom is that the mouth presents a rigorous environment. This is why dental restorative materials are confined to porcelain, precious metal alloys, chromium-based alloys, polymers or composites. The material has to be relatively inert, that is, it should have a high degree of passivity. 
If it does not it will not stand up when embedded in teeth. Even more rigorous passivity is required if the material is embedded in bone or soft tissue. Materials almost invariably fail as a restorative material if they will not withstand a watery environment, mild alkalis and organic acids in foods or resulting from degradation of foods. Hence some of the ceramic materials that are being developed should be given some standard laboratory tests prior to animal experimentation. Perhaps the test for the chemical resistance of containers-glass as given in the U. S. Pharmacopoeia or a slight modification of it would be considered as an initial screening test. Also consideration should be given to the ASTM Designation C225-59T Tentative Methods of Test for Resistance of Glass containers to Chemical Attack.

There is too much uncontrolled and undiscipined biological testing of biomaterials as so often the material that is being tested is not characterized even in the most elemental way.

Examples of Research on Test Methods

Silicate cement. Solubility is the chief defect of silicate cement, a life-like restorative material for the front teeth. Thus, the average life of a silicate cement restoration is roughly $4 \frac{1}{2}$ years. (3) Therefore, solubility is one of the pertinent properties and requires research to design a laboratory test that will evaluate in a short time the long term behavior of a silicate cement restoration in the mouth.

First one must set up a standard test consistency based upon the powder/liquid ratios in common usage. Of course all such tests have to use amounts of cement comparable to that 
which the dentist uses. Hence the test specimens are small compared to customary test specimens.

The consistency was determined on a parallel plate viscometer (Fig. 1) ${ }^{(4)}$ using the diameter of the slumped mass as the numerical designation of the consistency. Of course, no such apparatus was available--one had to be designed. The diameter of the disk varied according to the powder/liquid ratio used under standard experimental conditions which closely followed clinical practice. Curves showing the relationship between the powder/liquid ratio and the diameter of the disk, the measure of the consistency, are presented in Figure $2^{(4)}$ for many cements. The consistency selected as the standard was, as before stated, the average used by practicing dentists.

After the standard consistency test was designed a test for solubility naturally followed. What should be the corroding liquid--water, artificial saliva, natural saliva, an aqueous solution of one of several organic acids, or of alkalis? All are present in the mouth. The first chosen liquid in which silicate specimens were immersed was distilled water and a test for weight loss was invented using disks suspended in tared weighing bottles (5) as shown in Figure 3. Here, in Figure 3 are two tared weighing bottles each containing two specimen disks in $50 \mathrm{ml}$ of distilled water. After storing the disks for one hour at a relative humidity of 100 percent at $37^{\circ} \mathrm{C}$ they are placed in the empty tared weighing bottle and weighed and then submerged in the water. After storage for one week (now for 24 hours) the specimens were removed, the weighing bottles dried at $149^{\circ} \mathrm{C}$ to constant weight and reweighed. The difference between the final and initial weight of the bottles was the amount of material lost 
from the cement. Values for six cements were determined for one week, then the same specimens were transferred to another tared weighing bottle and immersed in $50 \mathrm{ml}$ of distilled water for one week and the weight loss was determined again. This was repeated for 5 weeks and the totals computed as shown in Table 1. These are selected data from reference (4). Obviously the cements had a variety of solubilities but there were no clinical tests made to determine if these differences would be reflected in the mouth. Instead, it was reasoned that cements with low water solubility would be superior. Later, as it will be shown in the report, clinical tests confirmed this assumption.

Additional long time tests, up to 14 months, on compressive strength were carried out after submerging the specimens in distilled water, natural saliva and oil (Table 2). These data, too, are from reference (4). Generally an increase in strength proceeds from water to saliva to oil (immersed specimens). The solutions were changed each week. From these data it can be concluded that distilled water is a good immersion liguid because it is easily standardized and is more corrosive than natural saliva. This is needed in an accelerated test. Also data to compare long time with relatively short time test values, as provided in Table 2, are needed to fix maximum solubility values in a specification.

Several years later some clinical testing (6) was done, an example of which is shown in Figure 4. These two restorations were of the same silicate cement, were in the same environment and were placed by the same operator but were placed with two different procedures. The two procedures 
were devised at the desk and were based on purely laboratory findings. There is a great difference in the appearance of these two restorations which were apparent soon after the restorations were placed. Restoration A was made from a mix of cement spatulated for 30 seconds on a cool glass slab. Immediately after hardening the restoration was coated with petrolatum and was not dressed down flush with the enamel until five days later. Restoration $B$ was made from a mix spatulated for $l^{l} / 2$ minutes on a warm slab and was finished immediately after hardening.

The laboratory tests on which the handing procedures were based showed that a cement mixed on a cool slab had a higher powder/liquid ratio at a fixed consistency than a mix made on a warm slab. Thus, the mix made on the coolest slab had less solubility, was stronger, and shrank less than the mix made on the warm slab. Also mixing for a long time adversely affects the solubility and strength according to laboratory tests. The strength of cement increases rapidly with time especially in a few days. Hence the finishing should be delayed until the strength is sufficient to resist the disruption of the hard particles of unused powder imbedded in the comparatively soft matrix and to prevent the breakage of the margins during finishing.

As before stated all good and bad procedures are deductions from data derived from laboratory tests which are conventional, artificial and of short duration. Consider for instance the test for solubility which was just described. (5) Here disk-shaped specimens were immersed in distilled water for 24 hours, which is radically different from service test conditions in the mouth for several years. 
Likewise, the laboraotry test for strength is a static test in compression as several minutes are used in crushing the specimen. On the other hand, in the mouth the silicate cement restoration is subjected to a quickly applied and released load during mastication. Nevertheless a correlation between research findings and clinical practice has been demonstrated.

Another demonstration is shown in Figure 5 where two restorations side by side show about the same condition after $1^{1 / 2}$ years of service. The restoration in the larger tooth (the central incisor) was made from a cement having a water solubility of $0.5 \%$ and the restoration in the smaller tooth, the lateral incisor on the right, was made from a cement having a water solubility of 1.1\%. Figure 6 shows the same restorations after 4 years and 8 months without any apparent difference. This same patient, however, had restorations made of a cement with very high water solubility ( 3 to $5 \%$ ). The condition of restorations made with such a cement is shown in Figure 7 and portrays again a considerable degree of correlation between laboratory and clinical findings.

Color stability of dental resins

Hard rubber dominated the organic denture base field from the 1850's to the late 1930's when acrylic resins were first used. Since then, nothing has displaced acrylic resin because nothing has been developed with better properties.

In the late $1860^{\prime}$ 's celluloid was invented and found its way into denture bases. Then came phenol-formaldehyde dentures in 1924, the vinyls in 1932 and finally the acrylic resins in the $1930^{\prime} \mathrm{s}$. 
One always learns as much or more from failures than from successes. Consider the old celluloid material in Figure 8. (7) Notice the shrinkage and discoloration. This also occurred in the mouth. Figures 9 and 10 are two phenolformaldehyde dentures, Luxene 37 and Aldenol. The Luxene 37 turned orange in the mouth and the Aldenol turned black and they both shrank.

What was needed was an abusive laboratory test that would simulate such discoloration quickly. The old color stability test for plastics of the American Society for Testing Materials, as illustrated in Figure 11, was adopted.

This test has had a $100 \%$ clinical correlation for thirty years. Every denture base polymer that discolored in service in the mouth after many months or years of use likewise discolored about an equal amount in this test for color stability in 24 hours, and vice-versa every denture base polymer that did not discolor in service in the nouth after years of service did not discolor under this sun lamp.

When the cold-curing, sometimes called the self-curing acrylic polymers, were introduced they were tested under this sun lamp and discolored. They likewise discolored in service as can be seen in Figure 12 where the self-curing polymer was used as a repair material on a denture, the main base of which did not discolor in the mouth or during the laboratory testing. Later the self-curing denture base polymers were formulated that did not discolor under the test in the laboratory or in service.

\section{Strength of denture base resins}

As previously stated, in the late 1930's the acrylic resins made all of the other organic denture base materials obsolete so it was necessary to characterize the denture base acrylic polymers and formulate a standard for them. 
Here we shall treat only one aspect--strength. What type of strength should be used--compressive, shear, tensile, transverse, impact, fatigue, etc. The transverse test was selected because it probably simulates best the actual loading conditions in the mouth.

The specimen size and apparatus used in determining properties in transverse bending is shown in Figure 13. Notice that the tolerance on the dimensions of the specimen is fairly close on the thickness and on the width. The data obtained from such testing is shown graphically in Figure 14. The values for the transverse deflection in the original specification were based on such data because the acrylic resins in use in 1940 were certainly reasonably satisfactory in service. The data in Figure 14 are much later (10) - 1965, including other kinds of polymers which are or were used as denture bases. These data show definite differences in stiffness and strength. Naturaliy there is an inclination to select an organic denture base on the basis of high strength and low deflection values. However, clinical experience has shown that polymers with low strength and large deflection, like the self-curing acrylic resins, may hold up better in service than bases with high strength and low deflection. (11) This presents a good example of how physical data on symmetrical specimens may be misleading when applied to a Iabricated appliance. In this instance the denture is the fabricated appliance. It is composed of the base polymer and porcelain or polymer teeth. The porcelain and the denture base do not adhere and their thermal expansivity is vastly different. Methods of processing also affect the polymers. These considerations really make it necessary to do some physical testing on the denture and make it imperative to do clinical testing with centures also. 
But one cannot do all of this testing immediately. Adequate testing of dentures in the mouth takes several years. So at first one must resort to a physical and chemical characterization of the available materials, select what properties are pertinent to their use in the mouth and make some arbitrary decisions on limiting values for the selected pertinent physical properties. Then as more extant knowledge becomes available and as new materials are developed or the old ones improved the specification or standard should be revised. All of the foregoing holds principally when one is attempting to formulate a standard for materials that have been in clinical use for some time. There are available some good impressions of the clinical behavior of the materials--dental amalgam being a good example.

Much of the foregoing holds true when a new material is introduced as happened in the case of the acrylic resins.

A common mistake is to use unreservedly test methods developed for one material in the evaluation of another material. Many examples exist where this has been done. one will be cited. When epoxy resins were introduced as denture base materials they were evaluated by the same test procedures which had been developed for the acrylic resins. sometimes this was acceptable. In other instances it was not. In the test for water absorption on acrylic resin denture base materials, the thin specimens $(0.5 \pm 0.1 \mathrm{~mm}$ thick) came into equilibrium with water in about 24 hours. Both the acrylic and the epoxy denture base resins had about $1.6 \%$ gain in weight in 44 hours. If the test was continued for 65 days there was little or no increase in the absorption of water 
by the acrylic resin denture base materials but the epoxy resin denture base material had absorbed about $4 \%$ by weight of water in sixty-five days as shown in Table 3. (10)

Water absorption is usually accompanied by expansion of the resin. This did occur in dentures in the mouth. (12)

This expansion was determined on dentures fitted with stainless steel pins (Figure 15) on which reference lines were ruled. The linear changes in dimension were measured on a toolmaker's microscope (Figure 16). With such a procedure the data on the graph (Figure 17) were obtained. It would appear from this dimensional history that from the time the dentures were wax models in the flask until they had been used for seven years, that the epoxy resin dentures gradually expanded. Dentures made of hard rubber continuously shrank and warped to a much greater extent than did the epoxy dentures. Warpage was measured by determining the difference between the percentage of linear change on the molar-to-molar and on the flange-to-flange distances.

These linear changes on the dentures occurred gradually. Neither the patients or the researchers, dentists in this instance, could detect the changes clinically. This is just another way of saying that the tissues followed the changes so there was little or no difference in serviceability.

\section{Summary}

Research is always needed in designing tests for characterizing biomaterials. These tests should simulate conditions of use as much as is practicable, must often be conducted when the material is subject to exaggerated service conditions, that is, be abusive, and must have satisfactory reliability and validity. 
The formulation of standards or specifications for new materials is usually more difficult than the preparation of such standards for materials that have been used for several years largely because of the uncertainty about the biocompatibility of the new material and its service performance over an extended time.

\section{Sources of information}

Those interested in learning of the sources of extant information in biomaterials in general but with special reference to dental materials may find references 13 to 20 helpful. 
Table 1

Solubility and Disintegration of Silicate Cements in Distilled water

(percentage loss in weight)

\begin{tabular}{|c|c|c|c|c|c|c|}
\hline \multirow{3}{*}{ CEMENT } & \multicolumn{5}{|c|}{ Time in water at $37^{\circ} \mathrm{C}$ in weeks } \\
\cline { 2 - 7 } & $\begin{array}{c}1 \\
\%\end{array}$ & $\begin{array}{c}2 \\
\%\end{array}$ & $\begin{array}{c}3 \\
\%\end{array}$ & $\begin{array}{c}4 \\
\%\end{array}$ & $\begin{array}{c}5 \\
\%\end{array}$ & $\begin{array}{c}\text { Total } \\
\text { Los }\end{array}$ \\
\cline { 2 - 7 } A & 3.0 & 0.6 & 0.4 & 0.4 & 0.3 & 4.7 \\
B & 0.6 & 0.2 & 0.1 & 0.1 & 0.1 & 1.1 \\
C & 2.4 & 0.3 & 0.2 & 0.2 & 0.1 & 3.2 \\
D & $2.8 \pm$ & 0.5 & 0.3 & 0.3 & 0.2 & 4.1 \\
E & 1.3 & 0.4 & 0.3 & 0.3 & 0.2 & 2.5 \\
\hline
\end{tabular}

\pm Other values on different batches ranged from 1.5 to $0.9 \%$.

These data on Solubility and Disintegration of Silicate Cements in Distilled Water are from Reference (4). 
Table 2

Effects of Different Immersion Media on the compressive Strength of Silicate cement with Time ${ }^{(4)}$

\begin{tabular}{|c|c|c|c|c|c|c|c|}
\hline \multirow[b]{4}{*}{ CEMENT } & \multicolumn{7}{|c|}{ I $m$ m $r s i \circ n$ ed $i a$} \\
\hline & \multicolumn{3}{|c|}{$\begin{array}{l}\text { Distilled } \\
\text { Water }\end{array}$} & \multicolumn{2}{|c|}{ Saliva } & \multicolumn{2}{|c|}{ Oil } \\
\hline & \multicolumn{5}{|c|}{$\mathrm{A} 9 \mathrm{e}$} & & \\
\hline & $\begin{array}{c}1 \\
\text { week }\end{array}$ & $\begin{array}{c}6 \\
\text { months }\end{array}$ & $\begin{array}{l}14 \\
\text { months }\end{array}$ & $\begin{array}{c}6 \\
\text { months }\end{array}$ & $\begin{array}{c}14 \\
\text { months }\end{array}$ & $\begin{array}{c}6 \\
\text { months }\end{array}$ & $\begin{array}{l}14 \\
\text { months }\end{array}$ \\
\hline$A=$ & 19,500 & 25,000 & 23,000 & 26,000 & 23,500 & 30,000 & 34,000 \\
\hline B & 19,500 & 22,500 & 24,000 & 24,000 & 24,500 & 29,000 & 28,500 \\
\hline C & 19,000 & 20,500 & 19,500 & 23,000 & 22,000 & 29,500 & 32,000 \\
\hline $\mathrm{D}$ & 21,500 & 21,000 & 19.500 & 24,000 & 25,000 & 23,500 & 24,500 \\
\hline $\mathrm{E}$ & 19,500 & 23,500 & 19,500 & 27,000 & 21,000 & 29,000 & 33,000 \\
\hline
\end{tabular}


Table 3

Water sorption at $37^{\circ} \mathrm{C}(10)$

\begin{tabular}{|l|c|c|c|}
\hline \multirow{2}{*}{ Material } & \multicolumn{2}{|c|}{ Sorption } & \\
\cline { 2 - 4 } & 24 hours & 65 days & Difference \\
\hline $\begin{array}{c}\text { Self-curing acrylic resin } \\
\text { Acralite 88 }\end{array}$ & 1.60 & 1.68 & 0.08 \\
$\begin{array}{c}\text { Heat curing acrylic resin } \\
\text { Duraflow }\end{array}$ & 1.54 & 1.60 & 0.06 \\
$\begin{array}{c}\text { Epoxy denture base resin } \\
\text { Epoxolon }\end{array}$ & 1.57 & 3.98 & 2.41 \\
\hline
\end{tabular}


References

1. Guide to Dental Materials and Devices, 1970-1971. 5th Ed. American Dental Association, 211 E. Chicago Avenue, Chicago, Ill. 60611 .

2. Charpy, Georges. Les cahiers des charges pour la réception des matières metalliques, Revue de Metallurgie Memoires 4:1041, 1907.

3. Paffenbarger, G. C. Silicate cement: an investigation by a group of practicing dentists under the direction of the A. D. A. Research Fellowship at the National Bureau of Standards, JADA 27: 1611 Oct. 1940.

4. Paffenbarger, G. C., Schoonover, I. C. and Souder, W. Dental silicate cements: physical and chemical properties and a specification. JADA 25:32 Jan 1938.

5. Paffenbarger, G. C., Swaney, A. C., Schoonover, I. C. and Dickson, G. American Dental Association Specification No. 9 for dental silicate cements, first revision, effective July 1950, JADA 40:186 Feb. 1950.

6. Paffenbarger, G. C. Some clinical applications of research findings in dental materials. Ohio Dental J. 33:218 sept. 1959 .

7. Souder, W. and Paffenbarger, G. G. Physical properties of dental materials. Circular C433, National Bureau of Standards, 1942. Superintendent of Documents (now out of print).

8. ASTM Designation D620-576. Tentative method of test for colorfastness of plastics to light. Volume 27, ASTM Standards 1964. American Society for Testing Materials, 1916 Race Street, Philadelphia, Pa.

9. Sweeney, W. T. and Paffenbarger, G. C. Tentative American Dental Association Specification No. 12 for denture base material, acrylic resin or mixtures of acrylic or other resins. JADA 28:325 Feb. 1941.

10. Woelfel, J. B., Paffenbarger, G. C. and Sweeney, W. T. Some physical properties of organic denture base materials. JADA 67:489 Oct. 1963. 
11. Woelfel, J. B., Paffenbarger, G. C. and Sweeney, W. T. Clinical evaluation of complete dentures made of 11 different types of denture base materials. JADA 70: 1170 May 1965.

12. Woelfel, J. B. and Paffenbarger, G. C. Expanding and shrinking 7-year old dentures: report of cases. JADA 81:1342 Dec. 1970 .

13. Journal of Dental Research, the bimonthly Journal of the International Association for Dental Research, 211 E. Chicago Ave., Chicago, Ill. 60611.

14. Philips, R. W. and Ryge, G. Adhesive Restorative Dental Materials. (Proceedings from a workshop sponsored by the Dental study section, National Institutes of Health, and supported by a grant from the National Institute of Dental Research.) Owens Litho Service, Spencer, Indiana. Published 1961.

15. Adhesive Restorative Materials II. (Proceedings from the second workshop sponsored by the Biomaterials Research Advisory Committee, National Institute of Dental Research.) Public Health Service Publication No. 1494 (1966). For sale by the supt. of Documents, U. S. Government Printing Office, Washington, D. C. 20402. Price $\$ 1.00$.

16. National Institute of Dental Research, Research Contracts Office, Room 403 Westwood Building, Bethesda, Md. 20014 will furnish a list of Clearinghouse numbers of the Reports of Research Contractors with N.I.D.R. Copies of these reports may be obtained from the National Technical Information Service, Springfield, Va. 22151.

17. Science Information Exchange, Smithsonian Institution, 300 Madison National Bank Building, 1730 M street N. W., Washington, D. C. 20036. This is a National Registry of Research in Progress where retrieval service for queries is available.

18. Gilmore, H. W. Text book of operative dentistry. The C. V. Mosby Co., st. Louis, Mo. 1967.

19. Schultz, L. G. et al. Operative dentistry. Lea \& Febiger, Philadelphia, Pa. 1966. 
20. Paffenbarger, G. C. Dental Cements, Direct Filling Resins, Composite and Adhesive Restorative Materials: A Resume. To be published in Journal of Biomedical Materials Research.

$$
* * *
$$




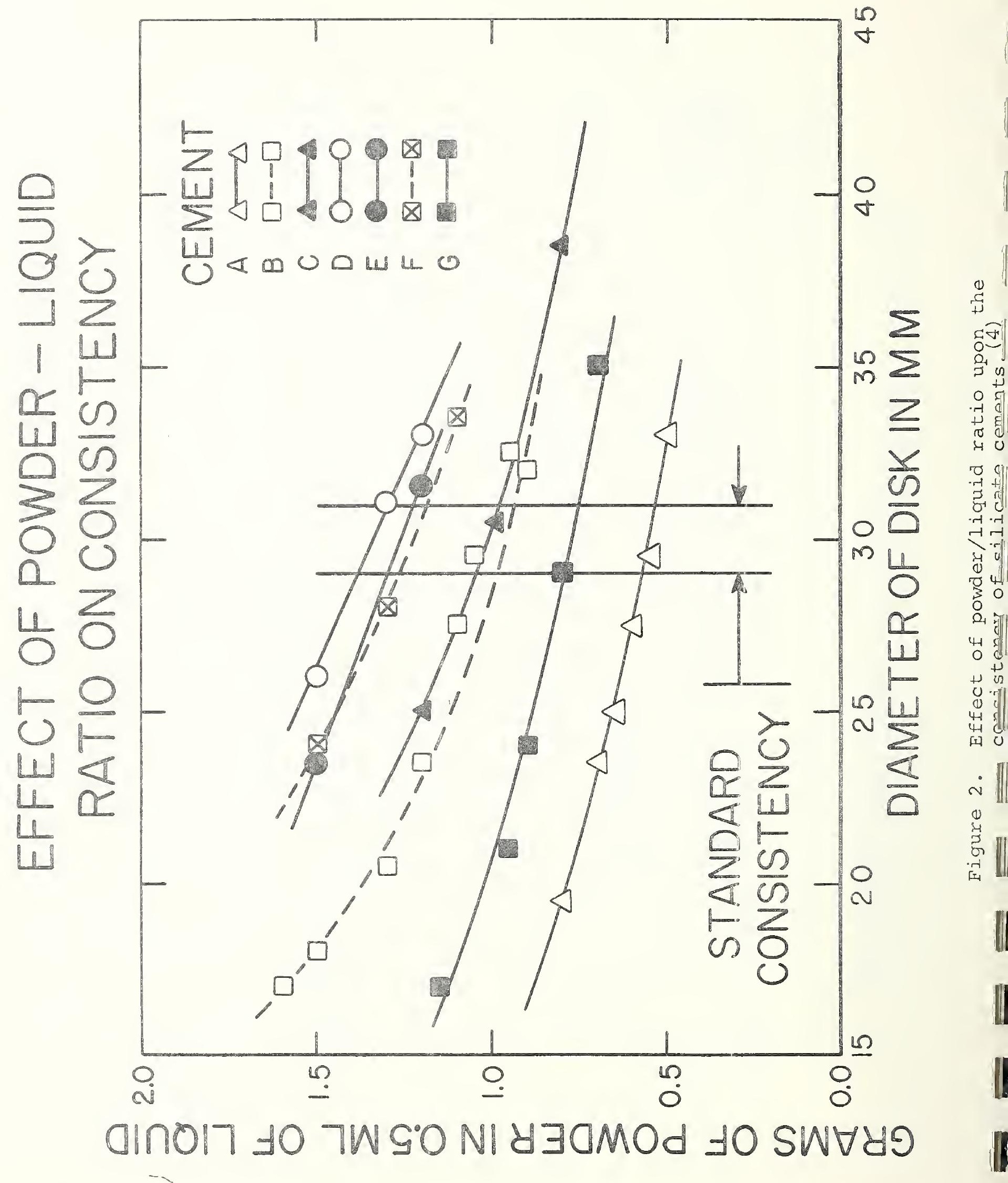




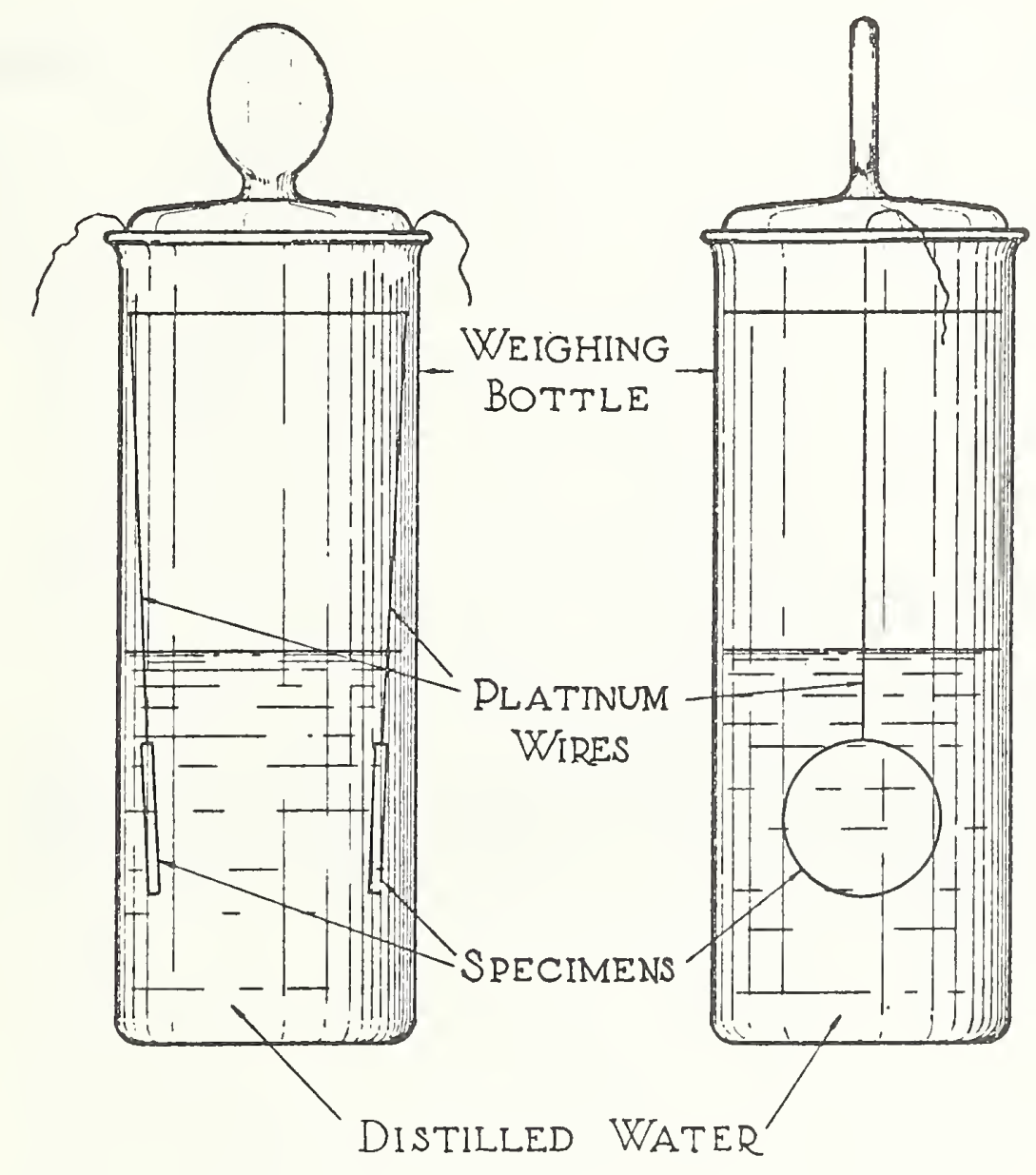

\section{Weighing Bottle Containing Solubility Specimens}

Figure 3. Weighing bottles containing solubility specimens of silicate cement. 


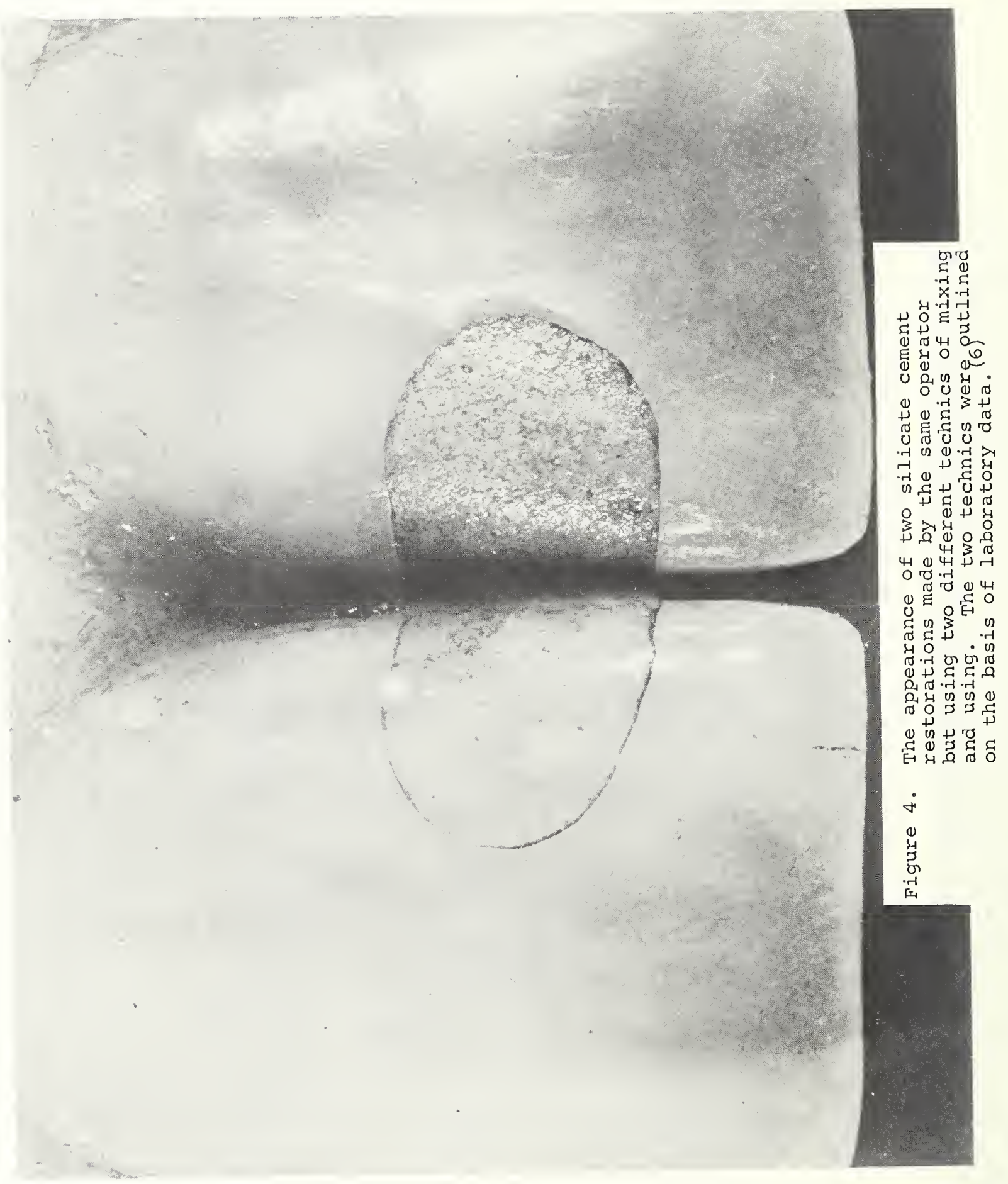





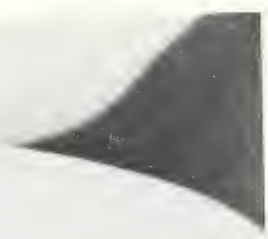

0
0
$0-1$
0
4
0
0
4
0
0
4
0
0
$>$
$m$
$\cdots$
+

4

俩

เก

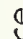

ชु

[ᄃ

ช

营

.

6

(1)

马ु

[I 


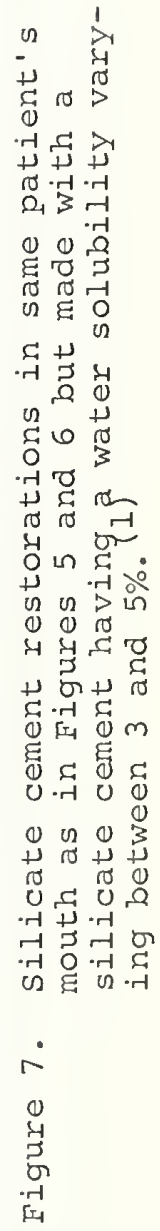




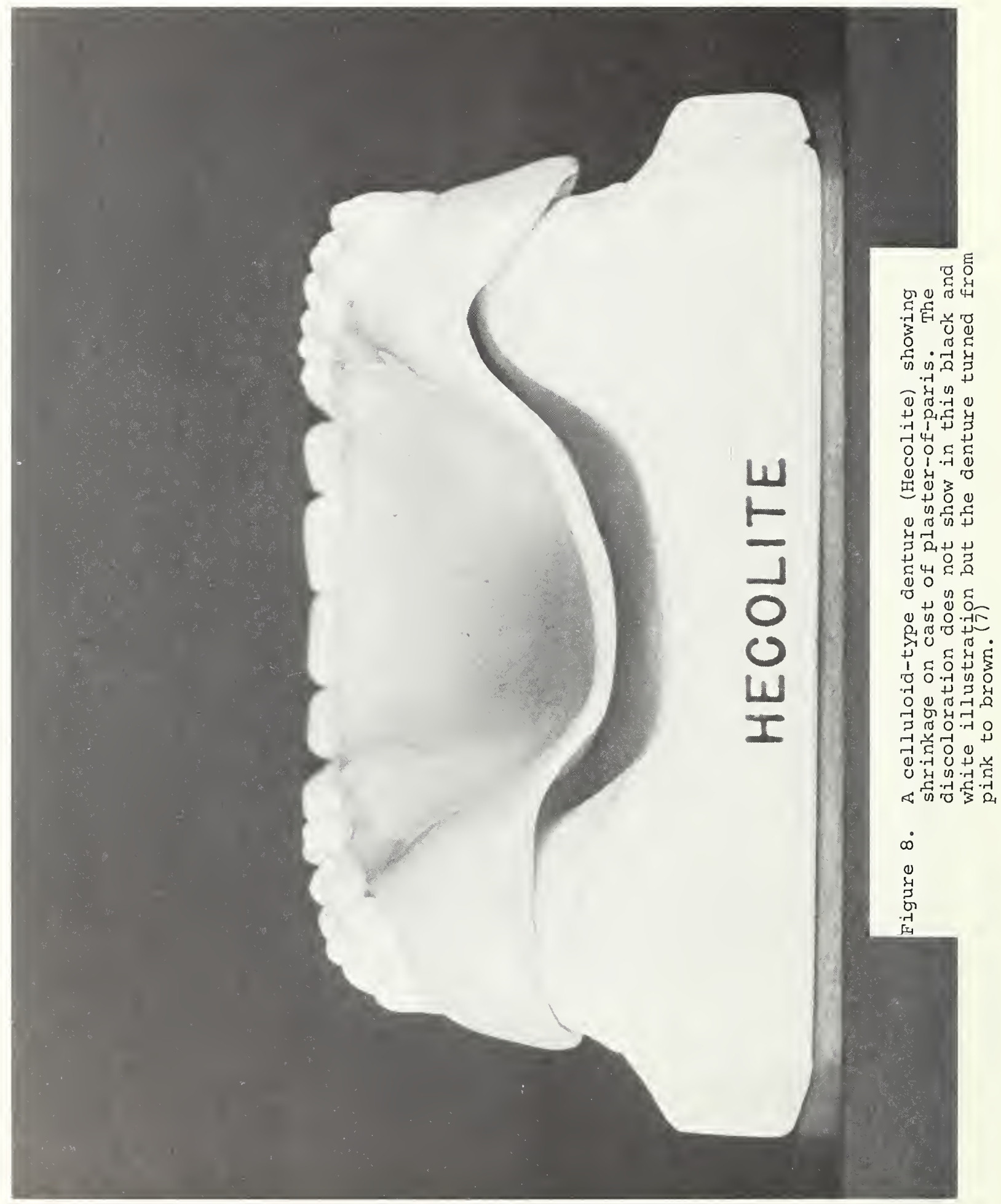




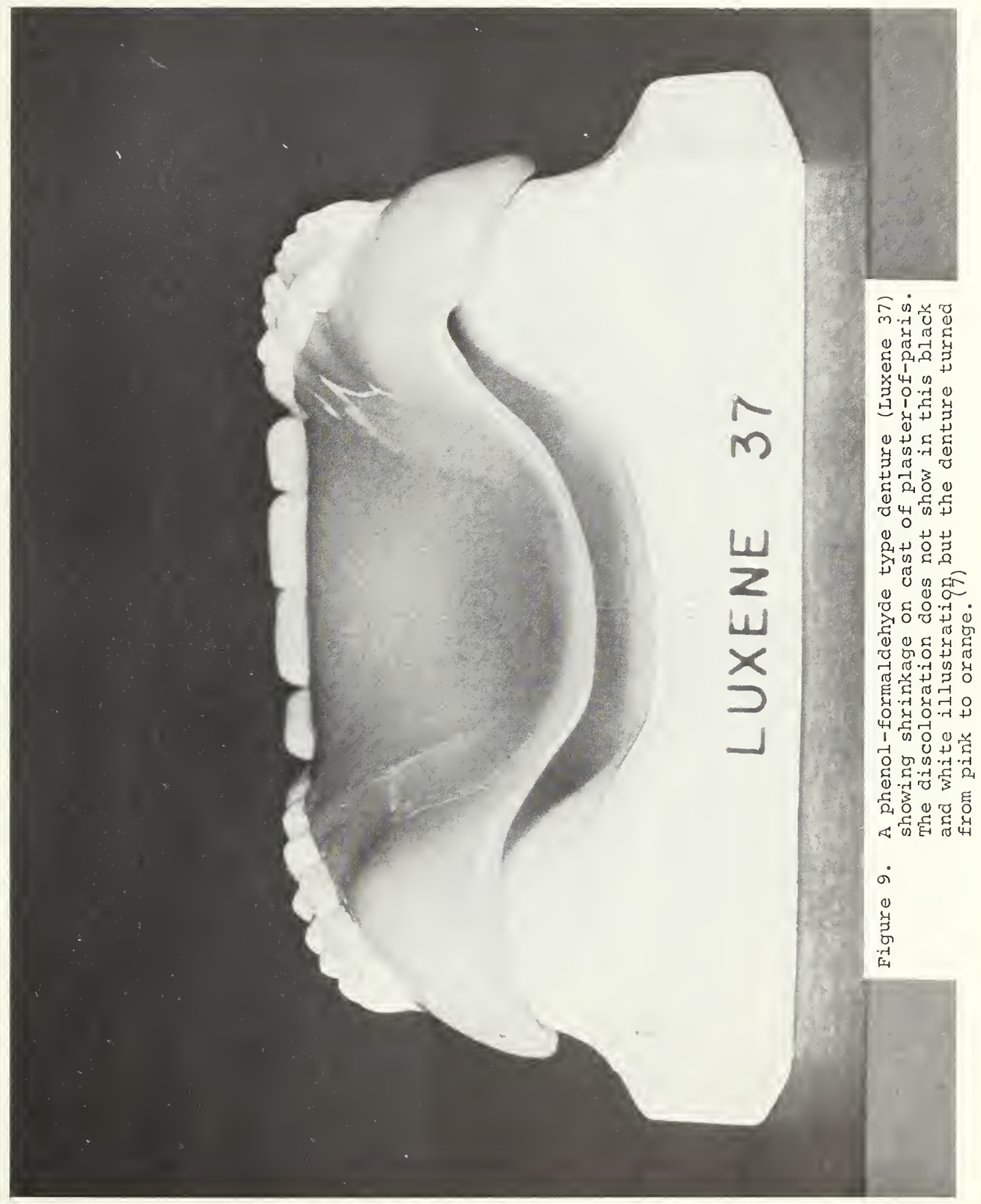




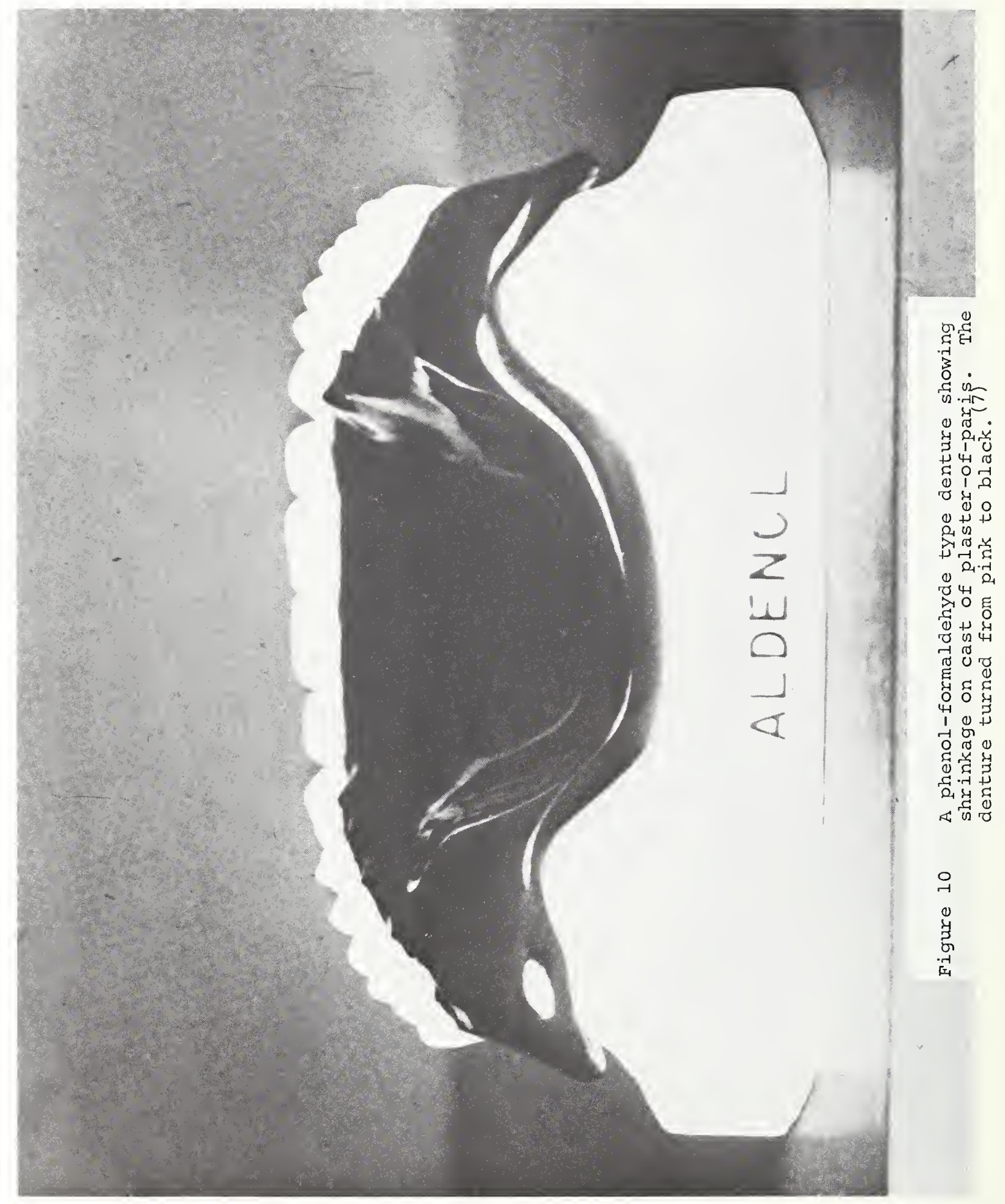




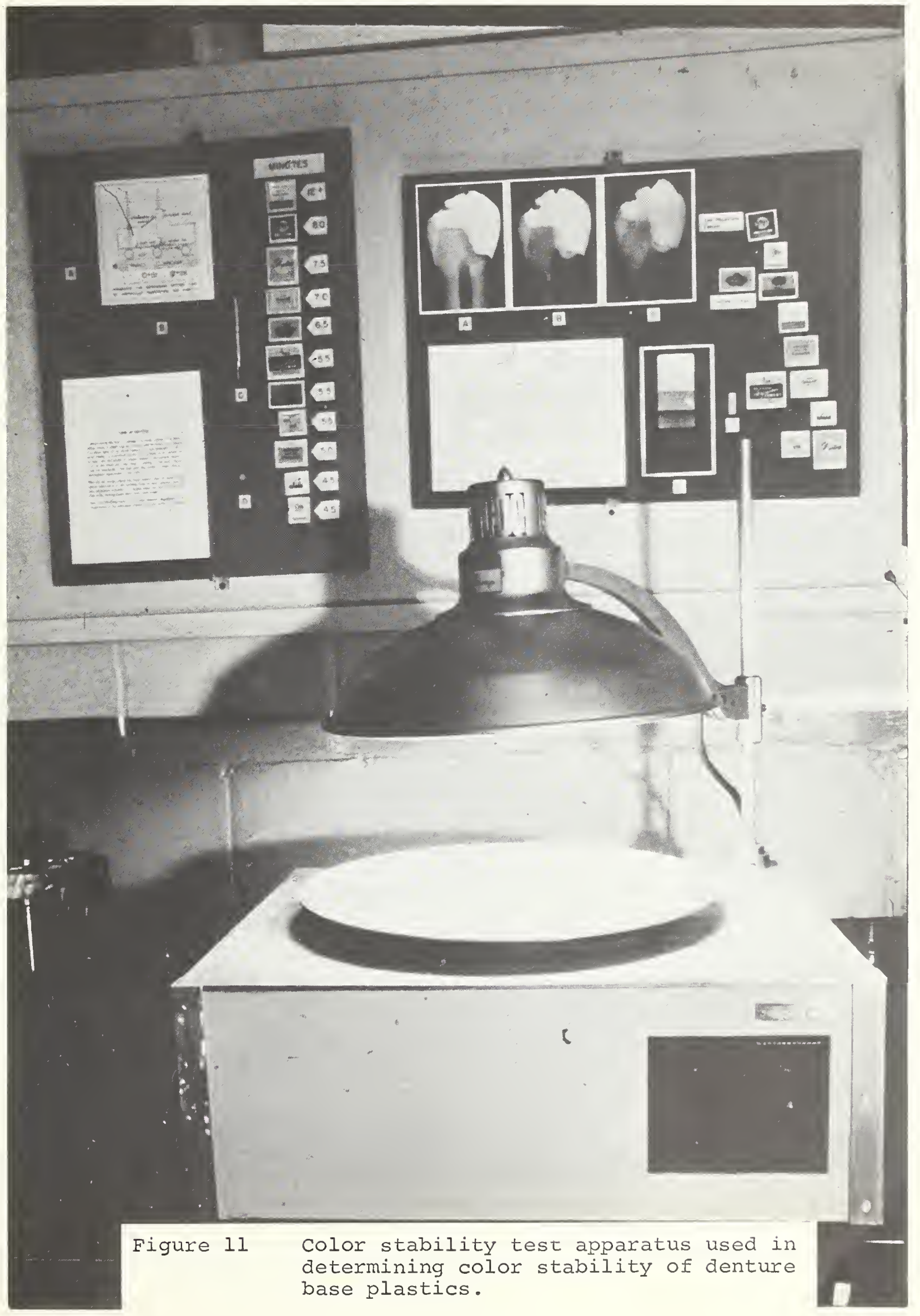




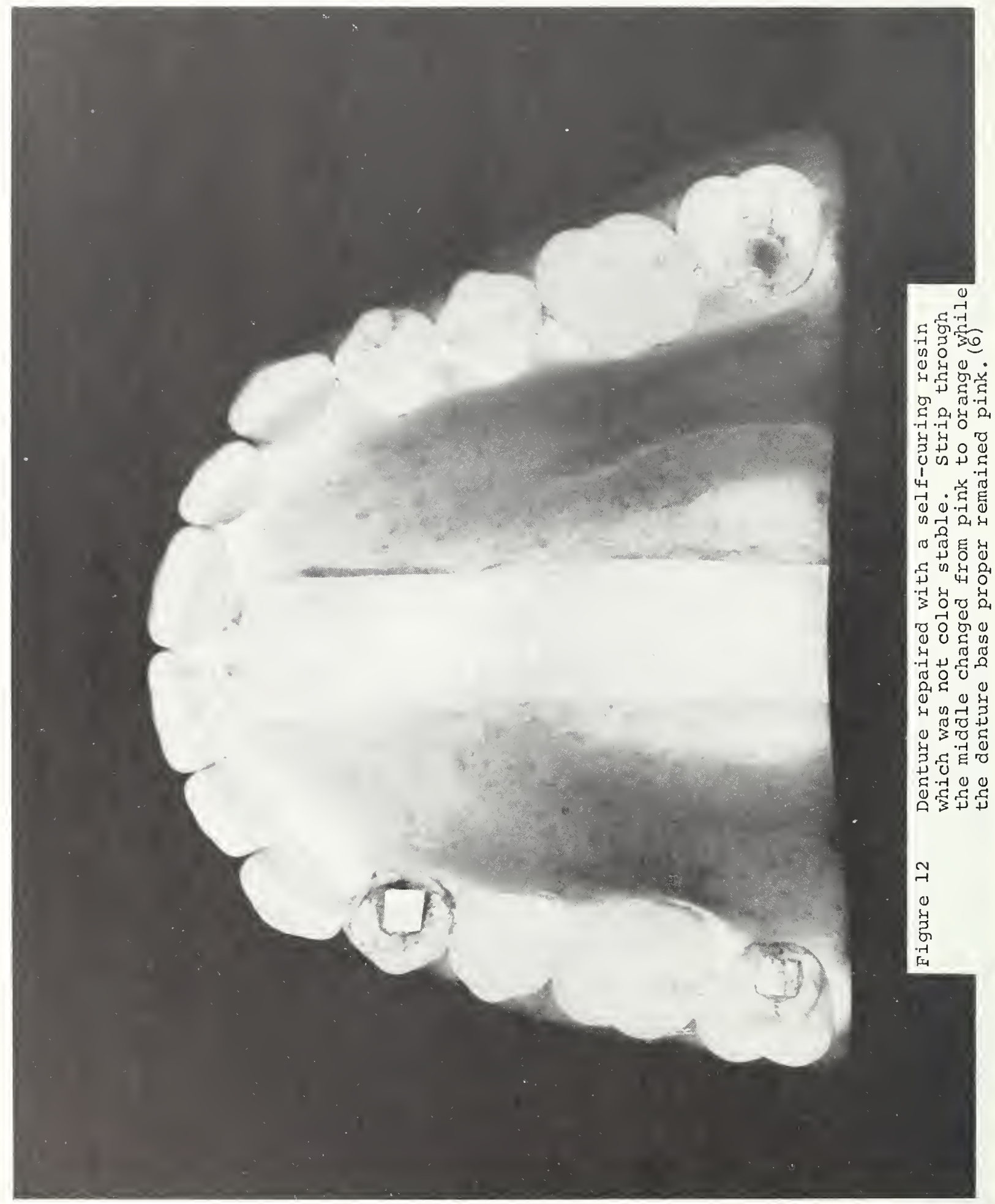



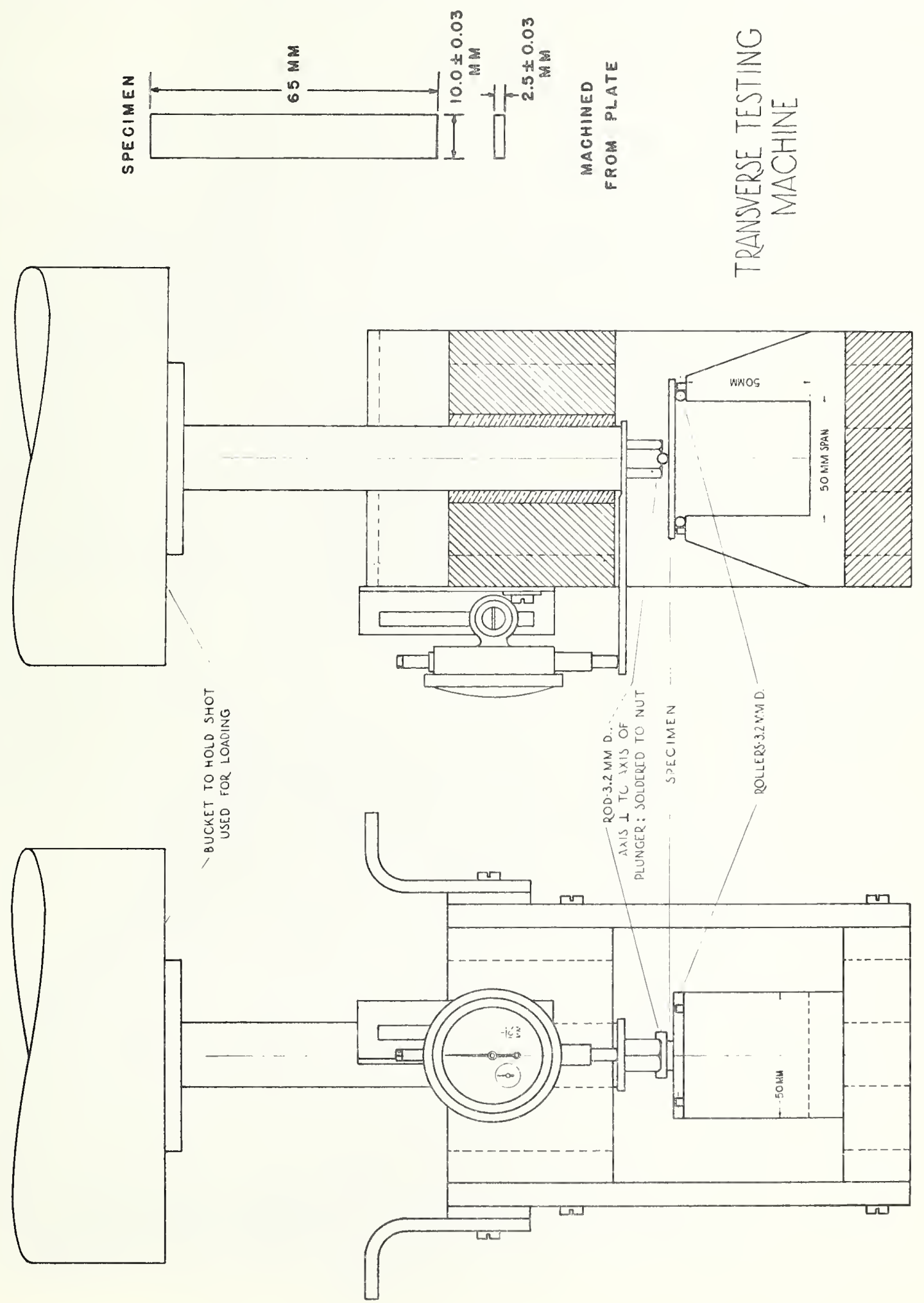


\section{TRANSVERSE TEST OF ORGANIC DENTURE BASES}

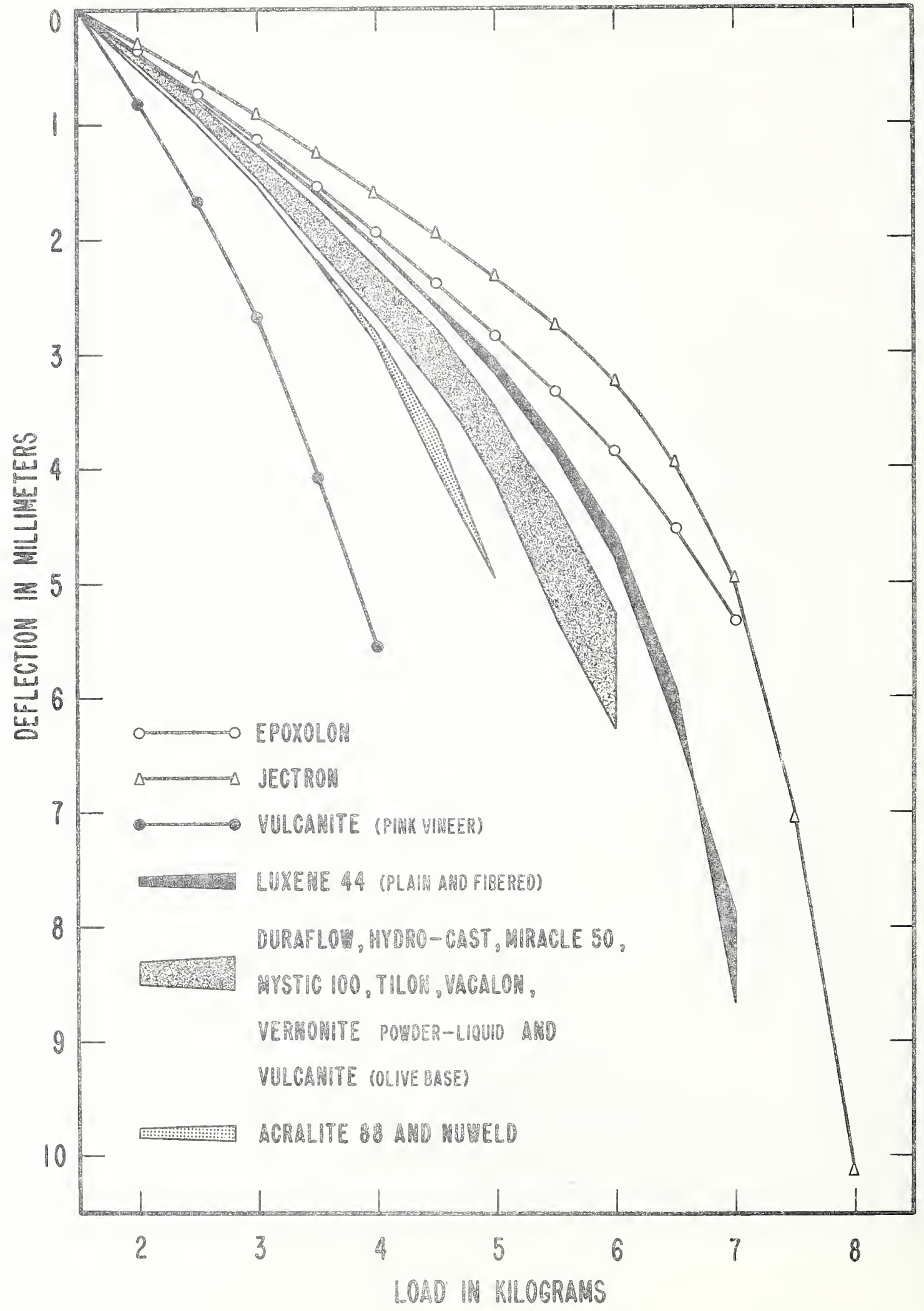

Figure l. Graphs showing the strength and stiffness of various organic denture base materials in transverse bending。(10) 


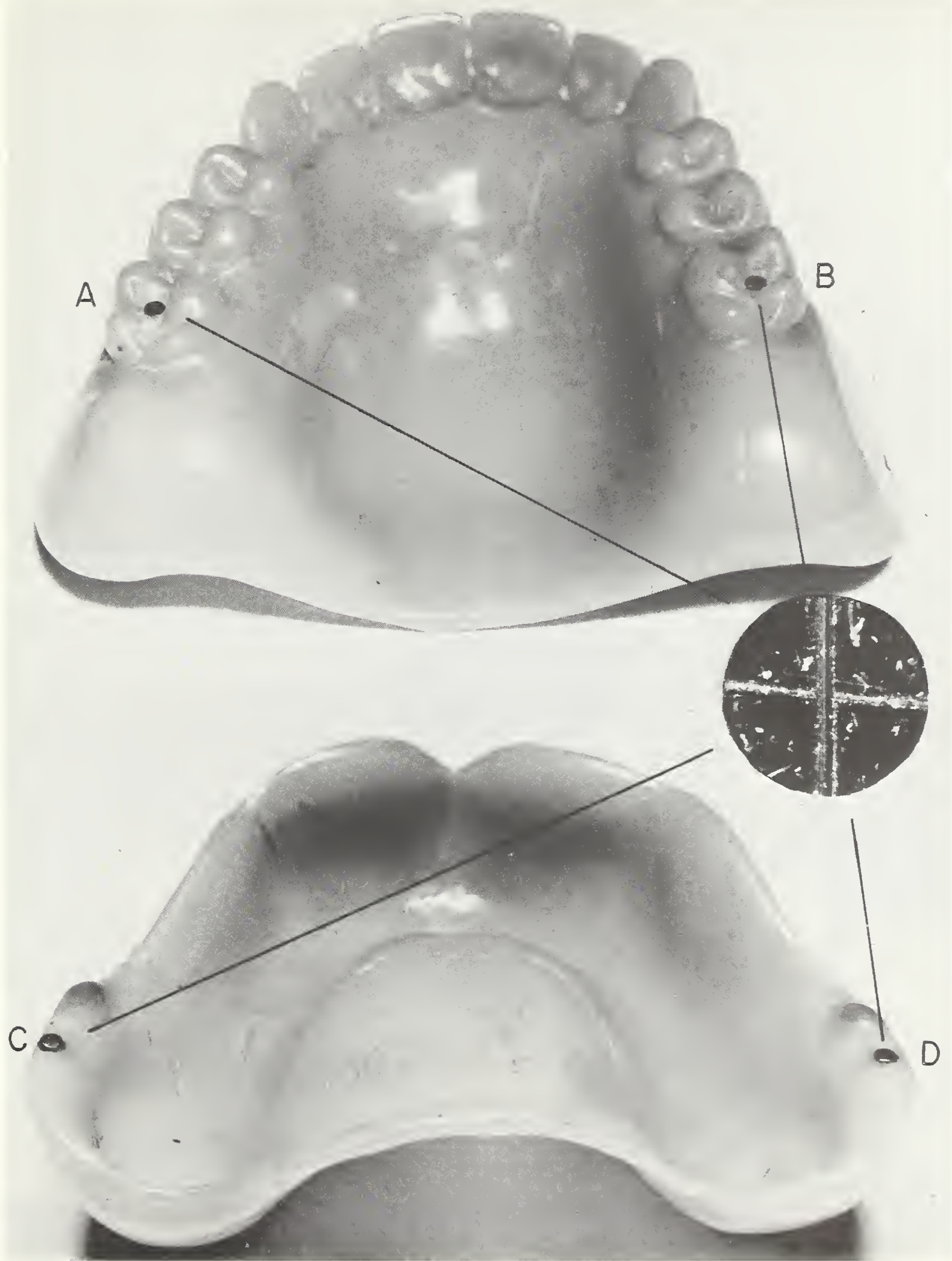

Figure 15

Experimental clinical denture with stainless steel reference pins used as reference points in measuring dimensional changes over $A B$ (molarto-molar) and CD (flange-to-flange) distances. 


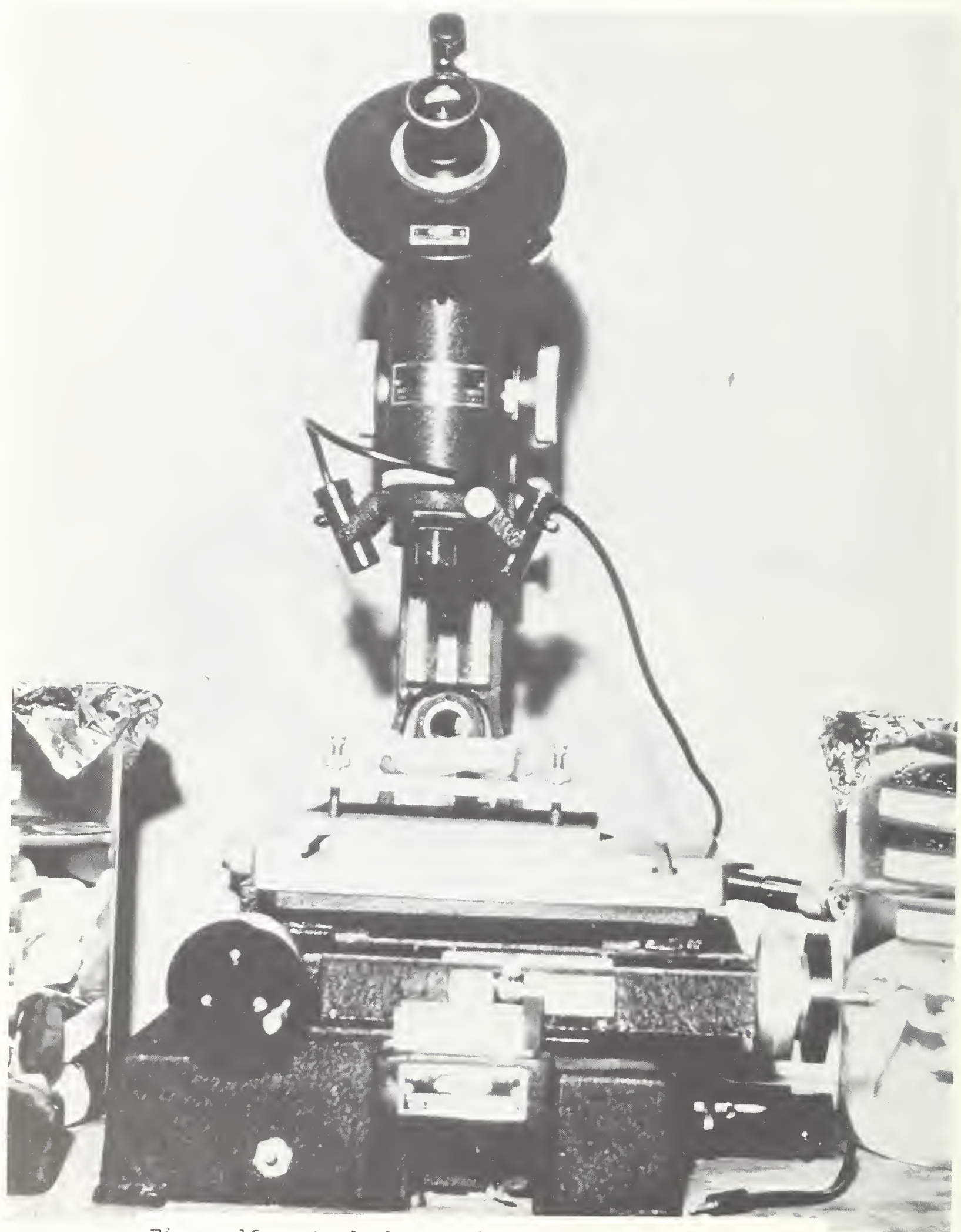

Figure 16 Toolmaker's microscope used in measuring dentures illustrated in Figure 15. 


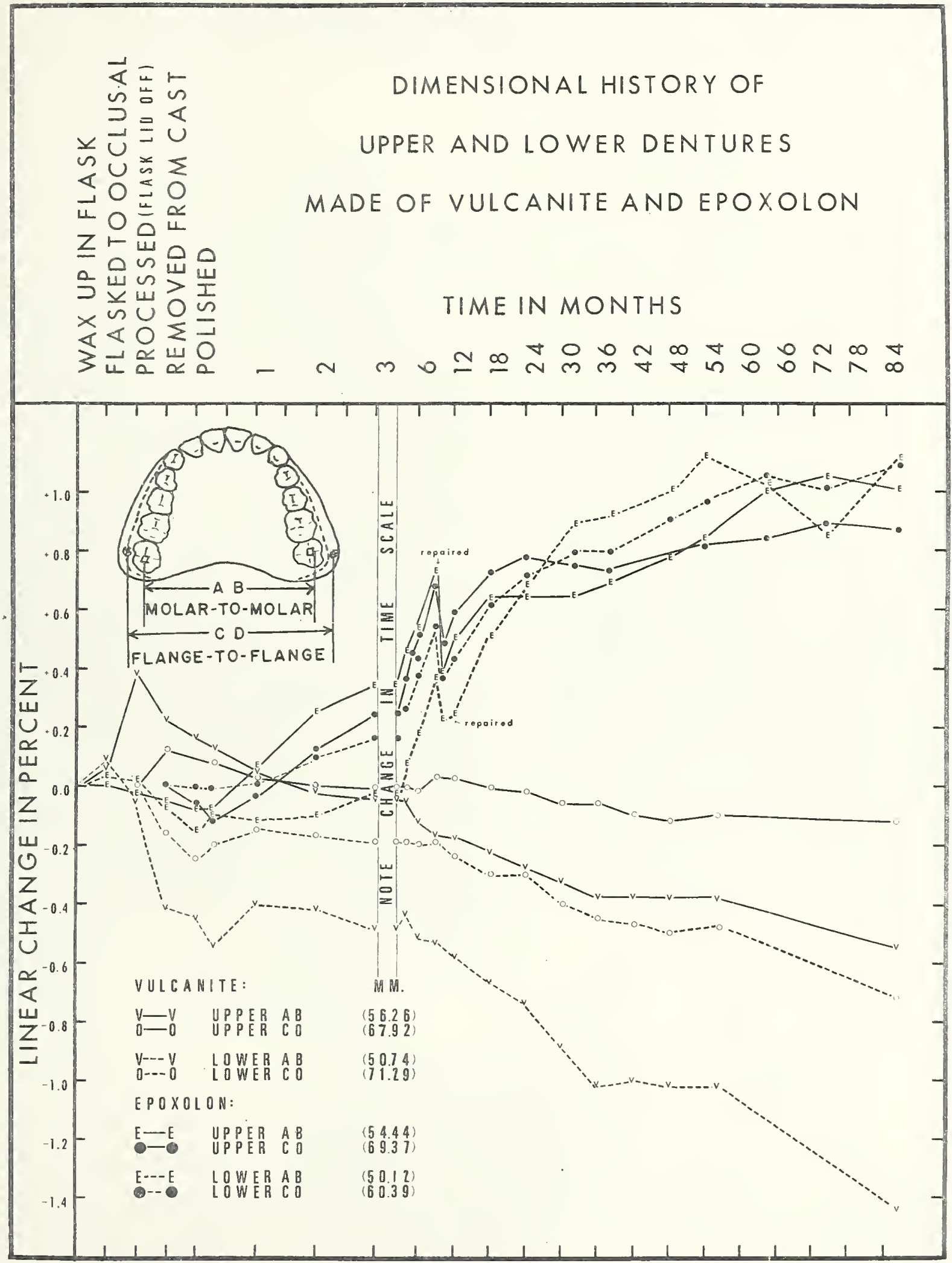

Figure 17 Dimensional history of expanding and contracting dentures after 7 years of service. 
